\title{
Comparative study of plasma leptin concentration between ruminal and abomasal feeding in sheep
}

\author{
T. Tokuda ${ }^{1}$, C. Delavaud ${ }^{2}$ and Y. Chilliard ${ }^{2}$ \\ ${ }^{1}$ Laboratory of Animal Science, Faculty of Life and Environmental Science, \\ Shimane University \\ Matsue-shi, 690-8504, Japan \\ ${ }^{2}$ Unit de Recherche sur les Herbivores, Equipe Tissu Adipeux et Lipides du Lait, INRA \\ Theix 63122 St-Gené-Champanelle, France
}

\begin{abstract}
Leptin plays an important role in regulation of energy balance in mammals. This experiment was conducted to investigate the difference between ruminal and abomasal feeding of plasma leptin concentration in ruminants. Plasma leptin, insulin and glucose concentrations showed different trends by conversion from ruminal to abomasal feeding in samples collected from sheep every 2 days at just before morning feeding throughout the experiment, and these concentrations were not stable in abomasal feeding. Plasma insulin and glucose increased dramatically after feeding in abomasal feeding than ruminal feeding, while plasma leptin did not show any change after feeding. Changes in plasma leptin concentration could be due to changes of the digestive system and/or changes in plasma insulin and glucose concentrations with following change of digestive system.
\end{abstract}

KEY WORDS: leptin, insulin, glucose, abomasal feeding

\section{INTRODUCTION}

Leptin, the protein product of the ob gene, plays an important role in the regulation of energy balance. Leptin is mainly secreted by adipose tissue, and ist levels in circulation are correlated with fat mass in humans, rodents (Maffei et al., 1995) and ruminants (Chilliard et al., 2001). In ruminants, the digestive system of the newborn is functionally similar to that of monogastric animals. On the other hand, mature ruminants utilize volatile fatty acids (VFAs) evolved by rumen fermentation instead of glucose as major substrates for energy and are almost

\footnotetext{
${ }^{1}$ Present address: Laboratory of Animal Production, Faculty of Bioresources, Mie University, Tsushi, 514-8507, Japan

${ }^{1}$ Corresponding author: e-mail: tomomi@bio.mie-u.ac.jp
} 
totally dependent on the glucogenic pathway for provision of glucose in the fed state as well as during fasting (Ballard et al., 1969). Therefore plasma glucose and insulin concentrations in mature ruminants hardly change post prandially unlike monogastric animals. Because circulating leptin has a strong relationship with insulin (Tokuda et al., 2002), the change from abomasal to ruminal feeding such as weaning of ruminants could bring some changes on plasma leptin concentration. When the young animal suckles milk from its dam or from an artificial device such as a teat, the liquid is channeled directly into the true stomach by a very elegant mechanism known as the oesophageal groove of the pre-developed rumen. If they were accustomed to drink milk by bottle feeding since they had been born, this behaviour continues even if after they were weaned and grown up. This experiment was conducted to investigate the difference between ruminal and abomasal feeding of plasma leptin concentration in ruminants.

\section{MATERIAL AND METHODS}

Three-mature and male sheep were used in this study. The experiment was proceeded by 2 weeks to adapt the animals to solid feed (AS-1 period), following by 4 weeks solid feed feeding (SF-1 period), 2 weeks adaptation of liquid feed (AL period), 8 weeks liquid feed feeding (LF-1 and 2 period), 2 weeks adaptation of solid feed (AS-2 period) and 4 weeks solid feed feeding (SF-2 period; Figure 1).

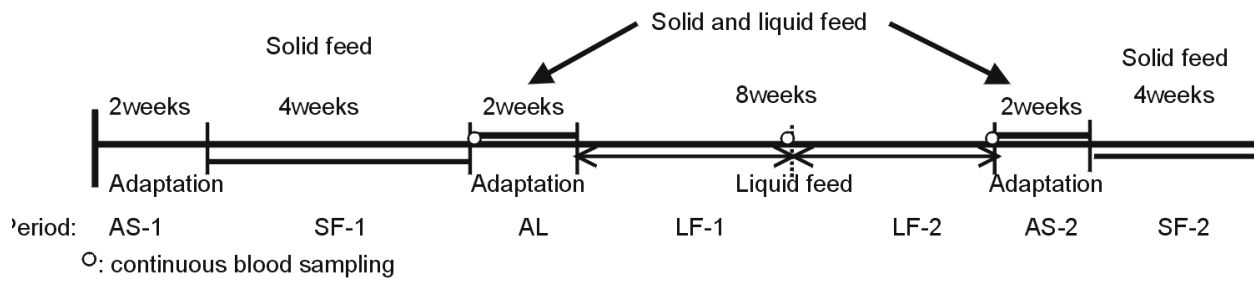

Figure 1. Experimental schedule

The sheep were fed 1.2 times of maintenance requirements of metabolizable energy and 1.2 times of maintenance requirements of crude protein throughout the experimental duration. They were accustomed to bottle feeding when they were suckling stage, and sheep were made utilization of feed energy similar to monogastric animal when they were fed liquid feed by bottle feeding methods. Fresh water and salt licks containing trace minerals were accessible at all times. Body weights were measured and recorded weekly throughout the experimental duration. Plasma samples were collected each 2 days throughout the experimental period, and for $10 \mathrm{~h}$ at 0,15 , $30,45,60,90,120,180,300,420$ and 600 min after morning feeding on the final day of SF-1, LF-1, LF-2 and SF-2 periods as indicated in Figure 1. 


\section{RESULTS AND DISCUSSION}

Plasma leptin, insulin and glucose concentrations showed high fluctuation during LF period, while their concentrations were quite stable during SF periods in plasma collected at just before morning feeding at each 2 days throughout the experiment. Plasma collected by continuous blood sampling at the final day of SF1, LF-1, LF-2 and SF-2 periods, plasma insulin concentrations increased $(\mathrm{P}>0.05)$

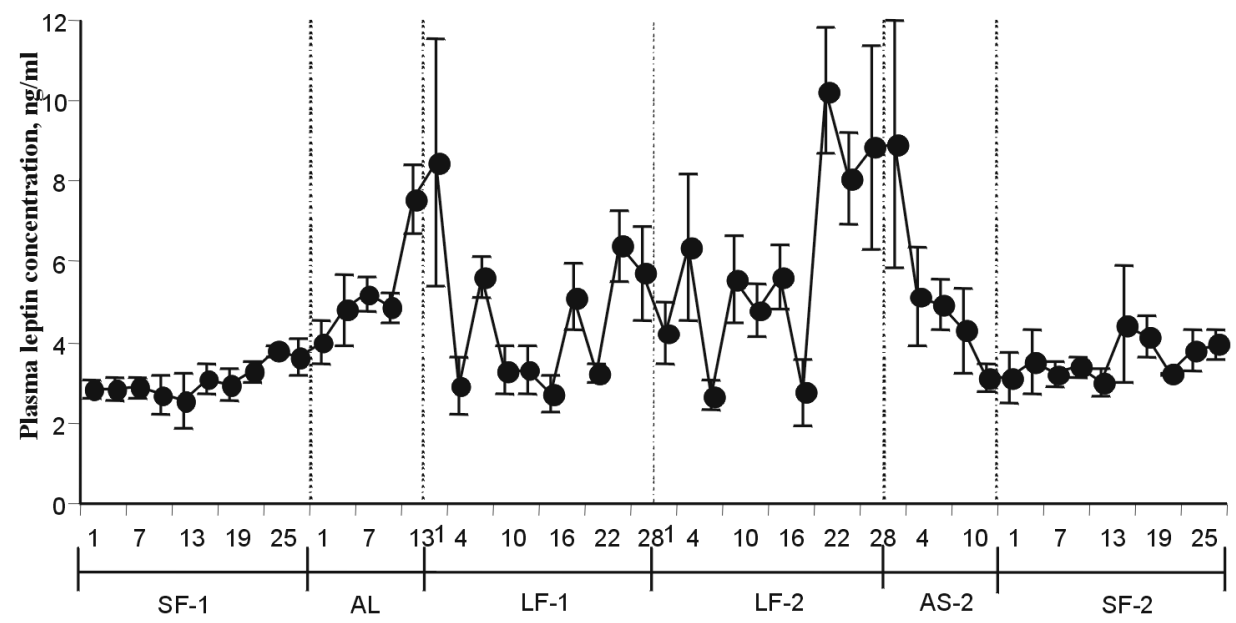

Figure 2. Changes in plasma leptin concentration throughout the experimental duration;

Data are means \pm S.E. for three sheep. Effect of period $(\mathrm{P}<0.05)$, effect of day $(\mathrm{P}<0.001)$ and effect of period day $(\mathrm{P}<0.0001)$ among $\mathrm{SF}-1, \mathrm{LF}-1, \mathrm{LF}-2$ and $\mathrm{SF}-2$ period;

The data was analysed by repeated measurements analyses of variance (ANOVA)

after feeding of SF and LF, and the rise of plasma insulin concentrations after feeding during LF-1 and LF-2 periods were more than 10 times higher than those at SF-1 and SF-2 periods. Plasma glucose at SF-1 and 2 periods did not change after feeding $(\mathrm{P}>0.05)$, while plasma glucose at LF-1 and 2 periods dramatically increased after feeding. Although plasma insulin and glucose concentrations showed drastic increase $(\mathrm{P}<0.05)$ after feeding during LF-1 and LF-2 periods, plasma leptin concentrations did not change $(\mathrm{P}>0.05)$ after feeding on both $\mathrm{SF}$ and LF periods. Plasma leptin concentrations were higher at LF periods than at SF periods throughout the blood collection time. It has been reported that plasma leptin do not change after feeding in human (Weigle et al., 1998) and mature ruminants (Tokuda et al., 2000). This result was similar with previous findings. Plasma leptin concentration increased by conversion from ruminal to abomasal feeding. Probably, changes in plasma leptin concentration could be due to changes of the digestive system and/or changes in plasma insulin and glucose concentrations with following change of digestive system. Ruminants at weaning 
encounter similar changes in digestive physiology as was found in the current work. Therefore, weaning could affect circulating leptin, make to decrease leptin concentration and contribute to stimulation of appetite in ruminants.

\section{REFERENCES}

Ballard F.J., Hansson R.W., Kronfeld D.S., 1969. Gluconeogenesis and lipogenesis in tissue from ruminant and nonruminant animals. Fed. Proc. 28, 218-231

Chilliard Y., Bonnet M., Delavaud C., Faulconnier Y., Leroux C., Djiane J., Bocquier F., 2001. Leptin in ruminants. Gene expression in adipose tissue and mammary gland, and regulation of plasma concentration. Domest. Anim. Endocrinol. 21, 271-295

Maffei M., Halaas J., Ravussin E., Pratley R.E., Lee G.H., Zhang Y., Fei H., Kim S., Lallone R., Ranganathan S., Kem P.A., Friedman J.M., 1995. Leptin levels in human and rodent: measurement of plasma leptin and ob mRNA in obese and weight-reduced subjects. Nature Med. 1, 1155-1161

Tokuda T., Matsui T., Yano H., 2000. Effect of light and food on plasma leptin concentrations in ewes. Anim. Sci. 71, 235-242

Tokuda T., Delavaud C., Chilliard Y., 2002. Effect of dietary levels on plasma leptin in sheep. Anim. Sci. J. 73, 471-478

Weigle D.S., Duell P.B., Connor W.E., Steiner R.A., Soules M.R., Kuijper J.L., 1997. Effect of fasting, refeeding, and dietary fat restriction on plasma leptin levels. J. Clin. Endocrinol. Metab. $82,561-565$ 